\title{
CRESCIMENTO INICIAL DE MUDAS DE Senna silvestris (Vell.) H. S. Irwin \& Barneby CULTIVADAS EM DIFERENTES SUBSTRATOS
}

\author{
Álisson Sobrinho Maranho'; Ary Vieira de Paiva² \\ (recebido em 24.09.2010 e aceito para publicação em 15.12.2011)
}

\section{RESUMO}

Face à importância do estudo sobre as espécies florestais nativas quanto às suas exigências aos fatores externos, o presente estudo teve por objetivo avaliar o crescimento de mudas de Senna silvestris, espécie arbórea com potencial para arborização urbana e revegetating em áreas degradadas, cultivadas em diferentes substratos. $O$ experimento ocorreu em delineamento inteiramente casualizado, com três substratos - areia, resíduo de açaí e o comercial Plantmax (tratamentos), repetidos 20 vezes, com uma plântula por saco plástico, acompanhadas por 90 dias. Os parâmetros avaliados foram altura, diâmetro do colo, pesos de massa seca da parte aérea, radicular e total, Índice de Qualidade de Dickson e relação altura por diâmetro do colo. Houve correlação positiva entre altura e diâmetro do colo das mudas para os substratos Plantmax $(r=0.51)$ e resíduo de açaí $(r=0.88)$. 0 substrato Plantmax proporcionou maior crescimento das mudas de Senna silvestris, quando avaliadas por todos os parâmetros.

Palavras-chave: Plantmax, resíduo de açaí, espécie florestal nativa, arborização urbana.

\footnotetext{
1. Graduando em Engenharia Florestal, Centro de Ciências Biológicas e da Natureza, Universidade Federal do Acre, Rio Branco - Acre, e-mail: alissonsobrinho@hotmail.com

2. Eng. Agr., D.Sc. Prof. do Centro de Ciências Biológicas e da Natureza, Diretor do Parque Zoobotânico, Universidade Federal do Acre, Rio Branco - Acre, e-mail: arypaiva1@yahoo.com.br
} 


\title{
INITIAL GROWTH OF Senna silvestris (Vell.) H. S. Irwin \& Barneby SEEDLINGS GROWN ON DIFFERENT SUBSTRATES
}

\begin{abstract}
Given the importance of studying native forest species external factors requirements, this study aims to evaluate the growth of Senna silvestris seedlings, a tree with potential use to urban forestry and revegetating degraded areas, grown on different substrates. The experiment was carried out in completely randomized design, with three substrates - sand, açaí waste and the commercial Plantmax (treatments), with 20 replicates, with one seedling per plastic bag, followed by 90 days. The parameters evaluated were shoot height, collar diameter, dry weights of shoot, roots and total, Dickson Quality Index and relation height/collar diameter. There was positive correlation between height and collar diameter of seedlings on substrates Plantmax $(r=0.51)$ and açaí waste $(r=0.81)$. The Plantmax substrate provided higher growth of Senna silvestris seedling, when evaluated by all parameters.
\end{abstract}

Keywords: Plantmax, açaí waste, native forest species, urban forest.

\section{INTRODUÇÃO}

O desmatamento em terras destinadas a diversas atividades econômicas e o crescimento do setor madeireiro indica a necessidade de produção de mudas características da região para seus mais variados fins, como recomposição de áreas degradadas e utilização na indústria madeireira, mas ainda há escassez de informações disponíveis sobre as técnicas mais adequadas para a produção de mudas de cada espécie, desde a coleta de sementes, substrato apropriado, até a condição mais favorável para a germinação e desenvolvimento das plântulas (FONSECA et al., 2006).

A exploração de uma espécie nativa depende de conhecimentos técnicos a respeito da propagação e do comportamento da mesma com relação às variações ambientais. Dados referentes ao tipo de substrato são fundamentais no processo de estabelecimento da 
muda (NOGUEIRA et al., 2003). O conhecimento das técnicas de produção de mudas constitui-se numa alternativa viável para recomposição efetiva das matas exploradas como forma de garantir, através dos sistemas de regeneração artificial, a continuidade deste potencial econômico (MUROYA et al., 1997).

O melhor método de produção de mudas de muitas espécies nativas ornamentais ainda não está totalmente estabelecido, necessitando de pesquisas quanto às suas exigências ao tipo de substrato, luminosidade, temperatura, tamanho de recipiente (ARRIGONI-BLANK et al., 2003), exigência nutricional, entre outros. São fatores muito importantes que permitirão o sucesso na propagação de mudas florestais de qualidade em viveiro.

A produção de mudas florestais, em qualidade e quantidade, é uma das fases mais importantes para o estabelecimento de bons povoamentos com espécies florestais nativas, bem como o entendimento do uso de substratos de cultivo apropriado (GONÇALVES; BENEDETTI, 2000).

O substrato é definido como o meio em que as plantas são cultivadas fora do solo, considerando como sua função primordial promover suporte, funcionando ainda como regulador da disponibilidade de nutrientes e de água (KÄMPF, 2000). A escolha do substrato é efetuada em função da facilidade e eficiência do uso do mesmo e da espécie a ser analisada (POPINIGIS, 1977).

Gonçalves e Benedetti (2000) afirmam que inúmeros substratos são usados atualmente para propagação de espécies florestais, e que algumas características são consideradas essenciais para um bom substrato como: boa estrutura e consistência; boa porosidade, mantendo adequada aeração junto ao sistema radicular; boa capacidade de retenção de água, não devendo se contrair excessivamente após a secagem; ser isento de substâncias tóxicas, inóculos de doenças, insetos, entre outros; estar prontamente disponível em quantidade adequada e custos economicamente viáveis; e deve ser bem padronizado, com características físicas a químicas pouco variáveis.

Senna silvestris (Vell.) H. S. Irwin \& Barneby é conhecida popularmente como ponçada ou fedegoso-do-mato, pertence à família botânica Fabaceae - Caesalpinioideae, tem porte arbóreo, atinge de 5-20 m de altura em matas e ao longo de rios, dotada de copa arredondada e baixa, de tronco curto de $20-30 \mathrm{~cm}$ de diâmetro, revestido com casca fina de cor acinzentada e lenticelada. As folhas são compostas pinadas de $30-60 \mathrm{~cm}$ de comprimento, com 7-11 pares de folíolos. Inflorescências em panículas terminais, com flores andróginas amarelas. Fruto legume deiscente e achatado com 20-30 sementes negras. 
Planta pioneira, heliófila, nativa, ocorre em todo o Brasil, em matas pluviais, florestas semidecíduas e cerrados, tanto em terra firme como em várzeas. A madeira é usada para caixotaria leve e para lenha. A árvore apresenta florescimento exuberante e muito ornamental, tendo grande potencial para o cultivo no paisagismo, particularmente na arborização urbana (LORENZI, 2009).

Face à importância do estudo das espécies florestais nativas quanto às suas exigências aos fatores externos, e o pouco conhecimento dos dados referentes à propagação e desenvolvimento desta espécie, o presente trabalho teve por objetivo verificar o crescimento de mudas de Senna silvestris cultivadas em três diferentes substratos: areia, resíduo orgânico de açaí e o comercial Plantmax.

\section{MATERIAL E MÉTODOS}

O experimento foi instalado no Viveiro de Produção de Mudas, no Parque Zoobotânico da Universidade Federal do Acre (UFAC), no interior de casa de vegetação.

As sementes utilizadas foram coletadas no mês de novembro de 2009 diretamente de árvores matrizes no interior do campus da UFAC, sendo levadas até o viveiro, lavadas e armazenadas em câmara fria até o momento de instalação do ensaio, que ocorreu após três dias.

Primeiramente realizou-se um tratamento pré-germinativo de superação de dormência, que ocorreu da seguinte forma: as sementes foram imersas em ácido sulfúrico concentrado (98\%) em um Becker por 30 segundos. Decorrido o tempo, as sementes foram retiradas, lavadas em água corrente, e postas para secagem em papel absorvente.

Logo após o tratamento pré-germinativo, ocorreu a semeadura em substrato areia, utilizando 100 sementes, em profundidade de $1 \mathrm{~cm}$, no espaçamento de $2 \times 2 \mathrm{~cm}$, dispostas em bandeja de plástico, no interior de casa de vegetação até atingirem tamanho suficiente para repicagem para os devidos substratos em teste. Aos 25 dias da semeadura, as mudas já apresentavam as primeiras folhas, fez-se então a repicagem.

Os substratos utilizados foram: areia lavada e peneirada, resíduo orgânico de açaí peneirado, oriundo do beneficiamento do fruto do açaí para produção de polpa, e o comercial Plantmax, colocados em sacos plásticos de polietileno preto, tamanho $17 \mathrm{~cm}$ de diâmetro x $25 \mathrm{~cm}$ de altura, com uma muda por recipiente. 
$\mathrm{Na}$ Tabela 1 é apresentada a análise química do resíduo de açaí utilizado no experimento, realizada pelo Laboratório do Departamento de Ciência do Solo da ESALQ/USP.

Tabela 1. Determinações totais dos elementos químicos presentes no resíduo orgânico de açaí utilizado no experimento

Table 1. Total determinations of the chemical elements present in açaí organic waste used in the experiment

\begin{tabular}{|c|c|c|c|c|c|c|c|c|}
\hline \multirow{3}{*}{$\begin{array}{c}\mathbf{p H} \\
\mathrm{CaCl}_{2}\end{array}$} & \multirow{3}{*}{$\begin{array}{c}\text { Densidade } \\
\mathrm{g} \mathrm{cm}^{-3}\end{array}$} & \multirow{3}{*}{$\mathbf{C} / \mathbf{N}^{*}$} & \multicolumn{6}{|c|}{ Macronutrientes } \\
\hline & & & \multirow{2}{*}{$\frac{\mathbf{N}}{\mathrm{gdm^{-3 }}}$} & $\mathrm{P}_{2} \mathrm{O}_{5}$ & $\mathrm{~K}_{2} \mathrm{O}$ & $\mathrm{Ca}^{+2}$ & $\mathrm{Mg}^{+2}$ & \multirow{2}{*}{$\frac{\mathbf{S}}{\mathrm{g} \mathrm{dm}^{-3}}$} \\
\hline & & & & \multicolumn{2}{|c|}{$\mathrm{mg} \mathrm{dm}^{-3}$} & \multicolumn{2}{|c|}{$\mathrm{cmol}_{\mathrm{C}} \mathrm{dm}^{-3}$} & \\
\hline 4.1 & 0.46 & $18 / 1$ & 8,5 & 2200 & 1000 & 6,1 & 0,7 & 0,2 \\
\hline \multicolumn{9}{|c|}{$\begin{array}{l}\text { Micronutrientes } \\
\mathrm{mg} \mathrm{dm}^{-3}\end{array}$} \\
\hline \multicolumn{2}{|c|}{$\mathrm{Cu}$} & Mn & $\mathrm{Zn}$ & \multicolumn{2}{|r|}{$\mathrm{Fe}$} & B & \multicolumn{2}{|r|}{$\mathrm{Na}$} \\
\hline \multicolumn{2}{|c|}{19} & 368 & 22 & \multicolumn{2}{|c|}{3219} & 4 & \multicolumn{2}{|r|}{158} \\
\hline
\end{tabular}

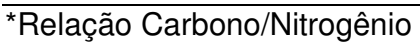

$\mathrm{Na}$ Tabela 2, citada por Negreiros et al. (2004), podem ser observadas as características químicas do substrato Plantmax.

Tabela 2. Propriedades químicas do substrato Plantmax

Table 2. Chemical properties of commercial substrate Plantmax

\begin{tabular}{|c|c|c|c|c|c|}
\hline \multirow{3}{*}{$\begin{array}{l}\mathbf{p H} \\
\mathrm{H}_{2} \mathrm{O}\end{array}$} & \multirow[b]{2}{*}{$\mathrm{Al}^{+3}$} & \multicolumn{4}{|c|}{ Macronutrientes } \\
\hline & & $\mathbf{P}$ & $\mathbf{K}$ & $\mathrm{Ca}^{+2}$ & $\mathrm{Mg}^{+2}$ \\
\hline & $\mathrm{Cmol}_{\mathrm{c}} \mathrm{dm}^{-3}$ & \multicolumn{2}{|c|}{$\mathrm{mg} \mathrm{dm}^{-3}$} & \multicolumn{2}{|c|}{$\mathrm{cmol}_{\mathrm{C}} \mathrm{dm}^{-3}$} \\
\hline 5,47 & 0,24 & 662,1 & 600 & 9,64 & 3,95 \\
\hline \multicolumn{6}{|c|}{$\begin{array}{l}\text { Micronutrientes } \\
\qquad \mathrm{mg} \mathrm{dm}^{-3}\end{array}$} \\
\hline \multicolumn{2}{|c|}{$\mathrm{Cu}$} & Mn & \multicolumn{2}{|c|}{ Zn } & $\mathrm{Fe}$ \\
\hline \multicolumn{2}{|c|}{0,79} & 21,4 & \multicolumn{2}{|c|}{22,62} & 210,3 \\
\hline
\end{tabular}

A irrigação aconteceu diariamente, considerando a umidade relativa do ar e o estágio médio de desenvolvimento das mudas, com o objetivo de manutenção da quantidade máxima de água que o substrato utilizado pode reter. 
Os parâmetros utilizados para avaliação das mudas foram a altura da parte aérea $(H)$, diâmetro do colo (DC), e aos 90 dias do início do experimento (repicagem) realizou-se a coleta do material, sendo determinados o peso de massa seca total (PMST), peso de massa seca da parte aérea (PMSPA), peso de massa seca das raízes (PMSR), a relação entre altura da parte aérea e o diâmetro do colo (H/D) e o Índice de Qualidade de Dickson (IQD).

A H e o DC foram medidos aos $0,30,60$ e 90 dias da instalação do experimento com um escalímetro, a partir do nível do substrato até a ponta da última folha, e por um paquímetro de precisão em décimos de milímetro. As determinações do PMSPA e do PMSR foram efetuadas a partir do material seco em estufa de ventilação forçada a $80^{\circ} \mathrm{C}$, por aproximadamente 24 horas. O PMST obteve-se a partir da soma das duas partes. A relação H/D foi determinada pela simples divisão entre os dois parâmetros.

O índice de qualidade de Dickson, que leva em consideração vários parâmetros, relacionando-os, foi obtido por meio da seguinte fórmula (CARNEIRO, 1995).

$$
I \mathrm{QD}=\frac{\text { PMST }(\mathrm{g})}{\mathrm{H}(\mathrm{cm}) / \mathrm{DC}(\mathrm{mm})+\operatorname{PMSPA}(\mathrm{g}) / \mathrm{PMSR}(\mathrm{g})}
$$

O delineamento experimental utilizado foi o inteiramente casualizado, com 3 tratamentos (substratos) repetidos 20 vezes. Os dados obtidos foram submetidos à análise de variância, correlação e as médias foram comparadas pelo teste de Tukey ao nível de 5\% de probabilidade.

Os dados, quando não apresentaram normalidade foram transformados para homogeneização dos resultados (SANTANA; RANAL, 2004), porém os apresentados nas tabelas são os dados originais. Para todas as análises foram utilizados os programas estatísticos Assistat 7.5 (SILVA, 2008), e Bioestat 5.0 (AYRES et al., 2007).

\section{RESULTADOS E DISCUSSÃO}

$\mathrm{Na}$ Tabela 3 são apresentados os dados referentes ao crescimento em altura e diâmetro do colo das mudas de Senna silvestris aos 90 dias após a repicagem. Verifica-se que houve diferença significativa, a partir do teste $F$, entre os substratos para todos estes parâmetros. 
Tabela 3. Crescimento médio em altura $(H)$, diâmetro do colo (DC) e relação altura por diâmetro do colo (H/D) das plântulas de Senna silvestris aos 90 dias

Table 3. Mean growth in height $(\mathrm{H})$, collar diameter $(\mathrm{DC})$ and relation height by collar diameter $(\mathrm{H} / \mathrm{D})$ of Senna silvestris seedlings to 90 days

\begin{tabular}{cccc}
\hline SUBSTRATOS & H (cm plântula $\left.{ }^{-1}\right)$ & DC $\left(\mathbf{m m}\right.$ plântula $\left.{ }^{-1}\right)$ & H/D \\
\hline AREIA & $9,79 \mathrm{~b}$ & $2,13 \mathrm{~b}$ & $4,75 \mathrm{~b}$ \\
RES. AÇAí & $8,34 \mathrm{~b}$ & $1,31 \mathrm{c}$ & $6,22 \mathrm{a}$ \\
PLANTMAX & $18,81 \mathrm{a}$ & $2,59 \mathrm{a}$ & $7,26 \mathrm{a}$ \\
\hline Valor de F & $35,2627^{\star *}$ & $57,9604^{* *}$ & $12,0041^{* *}$ \\
CV\% & 13,7464 & 7,7317 & 25,9068
\end{tabular}

**Teste F de Snedecor significativo a 1\% de probabilidade; as médias seguidas pelas mesmas letras não diferem entre si significativamente, pelo teste de Tukey, ao nível de 5\% de probabilidade; CV: Coeficiente de Variação.

O substrato comercial Plantmax proporcionou maior crescimento em altura das mudas, em média de 18,81 $\mathrm{cm}$ planta $^{-1}$, e foi estatisticamente diferente dos substratos areia e resíduo de açaí que apresentaram valores médios de altura inferiores.

Resultado semelhante foi obtido por Bezerra et al. (2004) em plântulas de Moringa oleifera quando cultivadas em substrato Plantmax, que proporcionou maior crescimento inicial em altura das mudas. Estudando a espécie Luehea divaricata, Grave et al. (2007) concluíram que é tecnicamente viável a propagação via sementes para esta espécie substrato Plantmax, o qual proporcionou maior crescimento e qualidade às mudas. Sabonaro e Galbiatti (2007) também observaram que substratos contendo Plantmax se mostraram eficientes para o crescimento de mudas de Tabebuia impetiginosa.

Carneiro (1995) recomenda que valores da relação H/D devem situar-se entre 5,4 e 8,1 , sendo assim mudas com desenvolvimento mais equilibrado e de melhor qualidade para o plantio. E quanto menor for o resultado dessa relação dentro deste intervalo, melhor deve ser a qualidade da muda.

Em substrato areia, as mudas apresentaram a menor relação $H / D(4,75)$, sendo estatisticamente diferente das demais, isto era esperado, uma vez que a areia não é boa fonte de nutrientes para as plantas, devido também às suas propriedades físicas relacionadas à alta drenagem e lixiviação, não proporcionando, portanto, um bom 
desenvolvimento das plântulas. Corroborando as recomendações de Carneiro (1995), os valores encontrados para as plântulas cultivadas neste substrato apresentaram-se abaixo do intervalo por ele recomendado, apresentando também baixíssima correlação linear entre o crescimento em altura e diâmetro do colo, como pode ser visto na Figura 1.

Figura 1. Correlação Linear de Pearson (r) entre o diâmetro do colo e altura das plântulas aos 90 dias, nos substratos areia (a), resíduo de açaí (b) e Plantmax (c)

Figure 1. Pearson linear correlation ( $r$ ) between collar diameter and height of seedlings to 90 days, on the sand (a), açaí residue (b) and Plantmax (c) substrates

(a) Substrato Areia

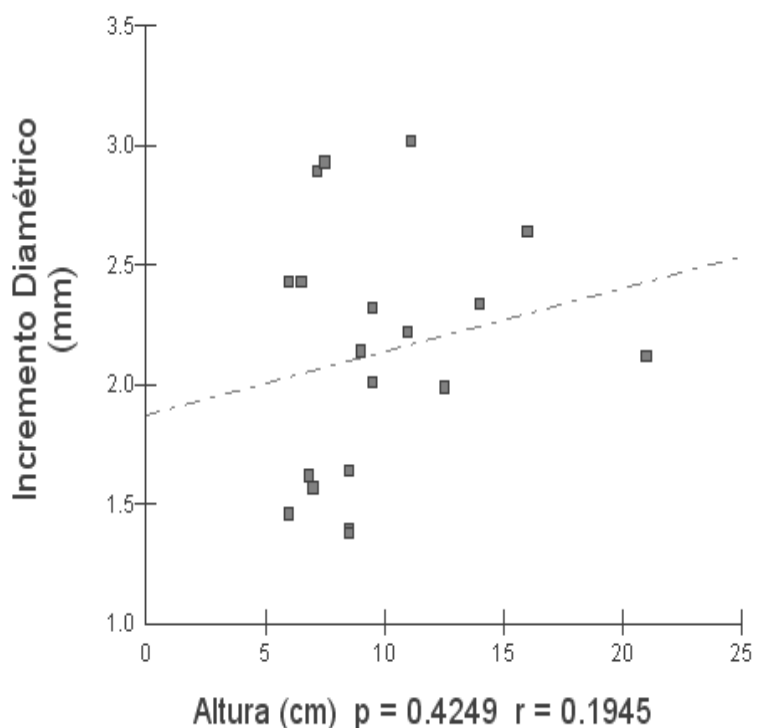

(c) Substrato Plantmax

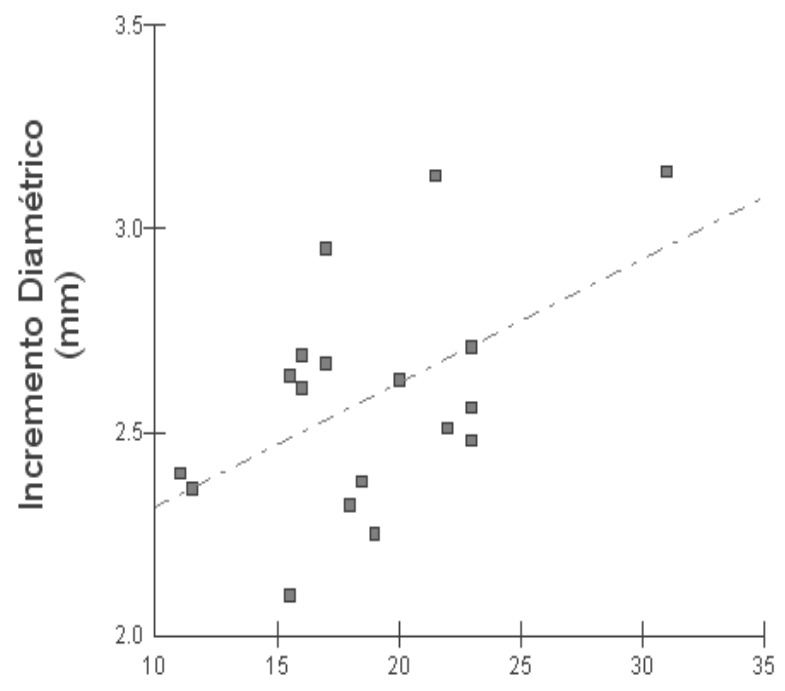

Altura $(\mathrm{cm}) \mathrm{p}=0.0293 \mathrm{r}=0.51$ (b) Substrato resíduo de açaí

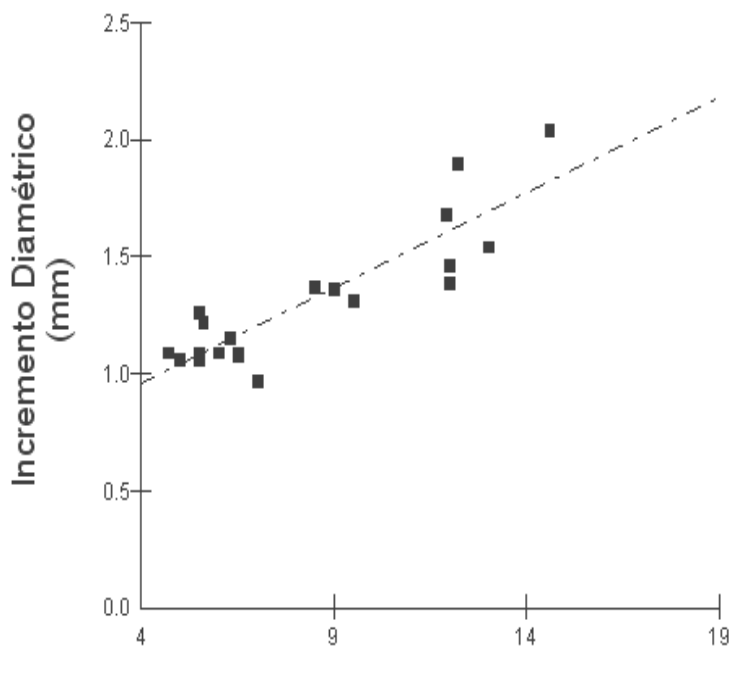

Altura $(\mathrm{cm}) \mathrm{p}<0.0001 \mathrm{r}=0,88$ 
Observa-se a partir da Correlação de Pearson, que no substrato areia, a correlação entre o diâmetro do colo e altura foi quase nula $(r=0,1945)$, isso quer dizer, que o incremento diamétrico foi independente do crescimento em altura, não havendo relação direta entre esses parâmetros, crescendo proporcionalmente mais em altura do que em diâmetro, o que demonstra não ser a areia o substrato mais adequado para produção de mudas com bom padrão de qualidade.

No substrato resíduo de açaí, a correlação foi positiva $(r=0,88)$, ou seja, as mudas tiveram desenvolvimento das duas partes, altura da parte aérea e diâmetro do colo, de forma mais uniforme, apesar de o crescimento em altura dessas mudas nesse substrato ter se apresentado inferior, possivelmente pela restrição de algum nutriente exigido pela espécie. A disponibilidade de nutrientes neste substrato, bem como a necessidade deles para o desenvolvimento da espécie deverão ser objeto de pesquisa em próximos trabalhos.

A correlação entre o DC e H também foi moderadamente positiva para o substrato Plantmax $(r=0,51)$ indicando também crescimento uniforme das duas partes.

Foram feitas medições da altura das mudas de Senna silvestris a cada 30 dias após a repicagem como se pode observar na Figura 2.

Figura 2. Crescimento em altura das mudas de Senna silvestris aos 0, 30, 60 e 90 dias após a repicagem, em diferentes substratos

Figure 2. Growth in height of Senna silvestris seedlings to $0,30,60$ and 90 days after subculturing, on different substrates

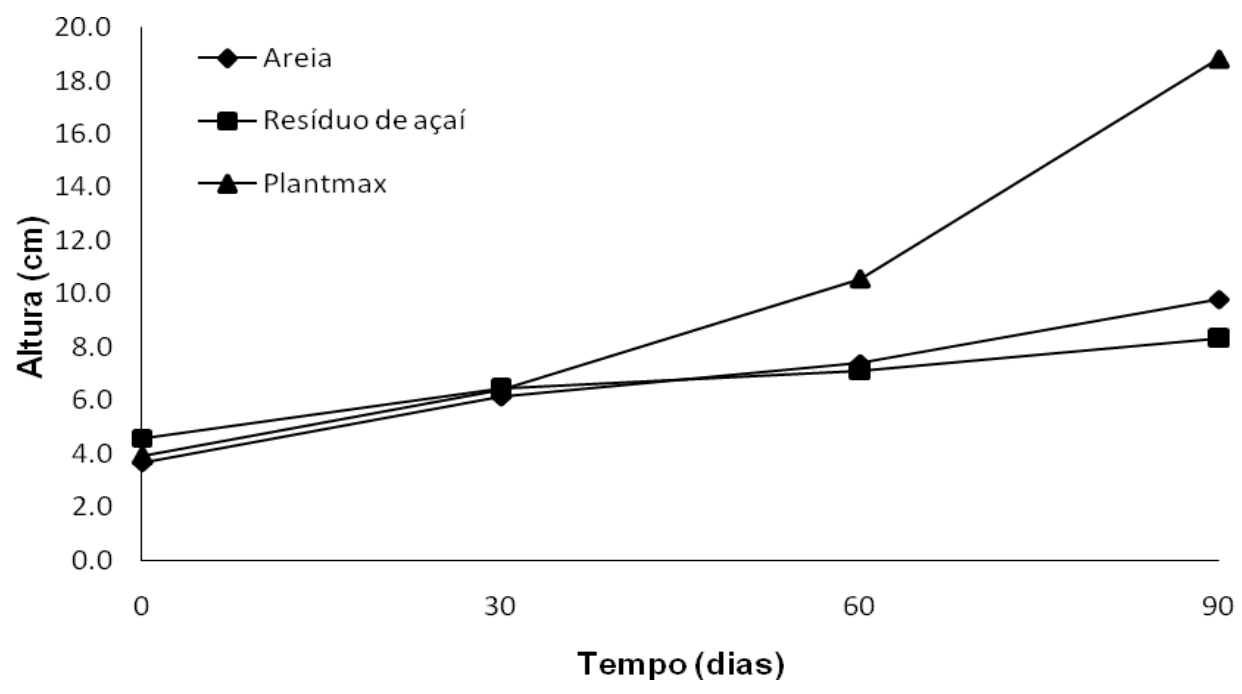


Até os 30 dias após a repicagem, as mudas apresentaram alturas semelhantes, sendo evidenciado o maior crescimento a partir dos 60 dias em mudas cultivadas em substrato Plantmax. Já os substratos areia e resíduo de açaí permitiram crescimento praticamente semelhante em altura das mudas durante todo o período do experimento.

Semelhante ao crescimento em altura, os maiores valores médios em diâmetro do colo foram obtidos das mudas em substrato Plantmax (2,59 mm planta ${ }^{-1}$ ), aos 90 dias após a repicagem, sendo estatisticamente diferente dos outros substratos, conforme observado na Tabela 3.

O diâmetro do colo é um parâmetro importante para avaliar o crescimento das mudas, embora ainda não existam padrões para este parâmetro, em função da inexistência de normas específicas para a produção de mudas florestais nativas no Brasil (PAIVA, 2005). O diâmetro do colo também foi obtido em medições a cada 30 dias após a repicagem das mudas, como pode ser observado na Figura 3.

Figura 3. Incremento diamétrico das mudas de Senna silvestris a cada 30 dias após a repicagem, em diferentes substratos

Figure 3. Collar diameter of Senna silvestris seedlings every 30 days after subculturing, on different substrates

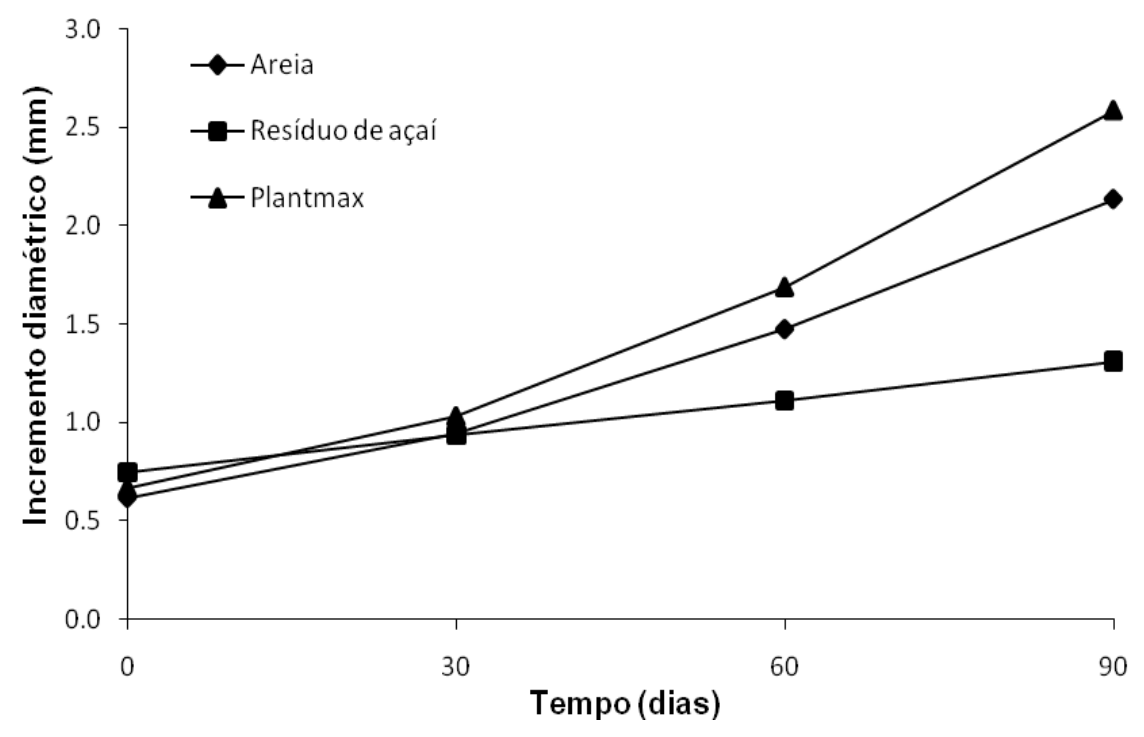


As mudas de Senna silvestris apresentaram diâmetro de colo semelhante nos três substratos até os 30 dias após a repicagem, sendo a maior diferença visível aos 90 dias no substrato Plantmax, proporcionando maior incremento a partir dos 30 dias.

Grave et al. (2007) também observaram progressivo incremento diamétrico em mudas de Luehea divaricata entre 60 e 180 dias de idade quando cultivadas em substrato Plantmax. Em Tabebuia impetiginosa, Sabonaro e Galbiatti (2007), verificaram que houve aumento expressivo do diâmetro do colo entre 90 e 150 dias após a semeadura também em substrato Plantmax.

A partir do teste $\mathrm{F}$, verificou-se que houve diferença significativa entre os substratos para os pesos de massa seca da parte aérea, raiz e total, e IQD como exposto na Tabela 4.

Tabela 4. Produção média de massa seca $\left(\mathrm{g} \mathrm{planta}^{-1}\right)$ da parte aérea (PMSPA), massa seca de raiz (PMSR) e total (PMST), e Índice de Qualidade de Dickson (IQD).

Table 4. Mean production of dry weights ( g seedling $^{-1}$ ) of shoot (PMSPA), roots (PMSR), and total (PMST), and Dickson Quality Index (IQD) of Senna silvestris.

\begin{tabular}{|c|c|c|c|c|}
\hline TRATAMENTOS & PMSPA & PMSR & PMST & IQD \\
\hline AREIA & $0,245 \mathrm{~b}$ & $0,099 \mathrm{~b}$ & $0,344 \mathrm{~b}$ & $0,047 \mathrm{~b}$ \\
\hline RES. AÇAÍ & $0,122 \mathrm{~b}$ & $0,037 \mathrm{~b}$ & $0,159 \mathrm{~b}$ & $0,016 \mathrm{~b}$ \\
\hline PLANTMAX & $1,218 \mathrm{a}$ & $0,261 \mathrm{a}$ & $1,479 a$ & $0,122 \mathrm{a}$ \\
\hline Valor de F & $81,5325^{\star *}$ & $34,6444^{* *}$ & $78,7732^{* *}$ & $48,8080^{* *}$ \\
\hline CV\% & 13,6953 & 6,5434 & 14,8536 & 2,9824 \\
\hline
\end{tabular}


A maior produção total de massa seca (PMST) foi de mudas cultivadas em substrato plantmax, bem como os PMSPA e PMSR, diferenciando-se estatisticamente dos substratos areia e resíduo de açaí, que proporcionaram produção média de massa seca total inferiores $\left(0,344\right.$ e $0,159 \mathrm{~g} \mathrm{planta}^{-1}$, respectivamente). Terra et al. (2007) obtiveram resultado semelhante em produção de massa seca da parte aérea e raiz, de mudas de Jacaranda mimosaefolia em substrato comercial.

Essa produção provavelmente tem relação com a maior quantidade de nutrientes que é fornecido pelo substrato comercial e de forma balanceada, principalmente nitrogênio, proporcionando maior crescimento em altura e do sistema radicular das plântulas.

O Índice de Qualidade de Dickson (Tabela 4) foi maior para as mudas de Senna silvestris cultivadas em substrato Plantmax e estatisticamente diferente dos demais substratos, que apresentaram valores inferiores e iguais entre si significativamente.

Juntamente com o substrato areia, o resíduo de açaí apresentou desempenho inferior quanto ao crescimento das mudas de Senna silvestris. Os resultados apontam a necessidade de se pesquisar o uso de substratos compostos, com participação do resíduo de açaí peneirado e outros produtos que complemente suas características físicas e químicas para a produção de mudas de qualidade.

\section{CONCLUSÕES}

O substrato comercial Plantmax influenciou positivamente o crescimento das mudas de Senna silvestris. Em todos os parâmetros avaliados, os melhores resultados foram obtidos em substrato Plantmax.

Houve correlação linear positiva mais expressiva entre altura e diâmetro do colo para mudas cultivadas nos substratos Plantmax e resíduo de açaí.

O resíduo de açaí puro não demonstrou ser adequado ao desenvolvimento de mudas da espécie, apontando para pesquisas de suas características físico-químicas que possibilitem composições com outros produtos, a fim de se alcançar as características desejadas que proporcionem melhor desenvolvimento das mudas. 


\section{REFERÊNCIAS}

AYRES, M. et al. Bioestat 5.0: aplicações estatísticas nas áreas de ciências biológicas e médicas. Belém: Sociedade Civil Mamirauá, MCT-CNPq, 2007.

ARRIGONI-BLANK, M. de F.; CARVALHO FILHO, J. L. S. de.; BLANK, A. F.; SANTOS NETO, A. L. dos. Efeitos do substrato e luminosidade na emergência e desenvolvimento de mudas de jasmim-laranja (Murraya exotica I.). Revista Ciência Agronômica, v. 34, n.1, 2003.

BEZERRA, A. M. E.; MOMENTÉ, V. G.; MEDEIROS FILHO, S. Germinação de sementes e desenvolvimento de plântulas de moringa (Moringa oleifera Lam.) em função do peso da semente e do tipo de substrato. Horticultura Brasileira, Brasília, v.22, n.2, p.295-299, abriljunho 2004.

CARNEIRO, J. G. de A. Produção e controle de mudas florestais. Curitiba: UFPR/FUPEF, 1995. 451p.

FONSECA, M. G.; LEÃO, N. V. M.; SANTOS, F. A. M. dos. Germinação de sementes e crescimento inicial de plântulas de Pseudopiptadenia psilostachya (dc.) G .P .Lewis \& M. P. Lima (Leguminosae) em diferentes ambientes de luz. Revista Árvore, Viçosa-MG, v.30, n.6, p.885-891, 2006.

GRAVE, F.; FRANCO, E. T. H.; PACHECO, J. P.; SANTOS, S. R. Crescimento de plantas jovens de Açoita-cavalo em quatro diferentes substratos. Ciência Florestal, Santa Maria, v. 17, n. 4, p. 289-298, 2007.

GONÇALVES, J. L. M.; BENEDETTI, V. Nutrição e Fertilização florestal. Piracicaba: IPEF, 2000.

KÄMPF, A. N. Seleção de materiais para uso como substrato. In: KÄMPF, A. N.; FIRMINO, M. H. Substratos para plantas: a base da produção vegetal em recipientes. Porto Alegre: Genesis, 2000. p. 209-215.

LORENZI, H. Árvores brasileiras: manual de identificação e cultivo de plantas arbóreas nativas do Brasil, vol. 3, Nova Odessa, SP: Instituto Plantarum, 2009.

MUROYA, K.; VARELA, V. P.; CAMPOS, M. A. A. Análise de crescimento de mudas de Jacareúba (Calophyllum angulare A. C. Smith - Guttiferae) cultivadas em condições de viveiro. Acta Amazônica, v. 27, n. 3, p. 197-212, 1997.

NEGREIROS, J. R. S.; ÁlVARES, V. de S.; BRAGA, L. R.; BRUCKNER, C. H. Diferentes substratos na formação de mudas de maracujazeiro-amarelo. Revista Ceres, v. 51, n. 294, p.243-345, 2004.

NOGUEIRA, R. J. M. C.; ALBUQUERQUE, M. B.; SILVA JUNIOR, J. F. Efeito do substrato na emergência, crescimento e comportamento estomático em plântulas de mangabeira. Rev. Bras. Frutic., Jaboticabal - SP, v. 25, n. 1, p. 15-18, Abril 2003.

PAIVA, A. V. Efeitos da aplicação de biossólido no crescimento e nutrição mineral de mudas de quatro espécies florestais nativas utilizadas na arborização urbana. 2005. 
136 f. Tese (Doutorado em Recursos Florestais) - Escola Superior de Agricultura Luiz de Queiroz, Universidade de São Paulo, Piracicaba, 2005.

POPINIGIS, F. Fisiologia da semente. Brasília: AGIPLAN, 1977. 289p.

SABONARO, D. Z.; GALBIATTI, J. A. Efeito de níveis de irrigação em substratos para a produção de mudas de ipê-roxo. Scientia forestalis, n. 74, p. 95-102, junho 2007.

SANTANA, D. G.; RANAL, M. A.; Análise da germinação: Um enfoque estatístico. Brasília: Universidade de Brasília, 2004. 248p.

SILVA, F. A. S. e. Assistat 7.5, 2008. Departamento de Engenharia Agrícola, UFCG. Disponível em: <http://www.assistat.com>. Acesso em: 15 jun. 2009.

TERRA, S. B.; GONÇALVES, M.; MEDEIROS, C. A. B. Produção de mudas de jacarandá mimoso (Jacaranda mimosaefolia D. Don.) em substratos formulados a partir de resíduos agroindustriais. Rev. Bras. Agroecologia, v.2, n.1, fev. 2007. 